\title{
Justicia divina: juicio y desacralización en el texto minificcional. Una lectura a la obra Guillermo Bustamante Zamudio
}

\author{
Divine justice: trial and desacralization in the minifictional text. \\ A reading of the work Guillermo Bustamante Zamudio
}

\author{
Wilfredo Illas Ramírez \\ Universidad de Carabobo-VENEZUELA \\ illasw@hotmail.com
}

\section{Resumen}

A propósito del texto minificcional "Justicia Divina”, perteneciente al libro Oficios de Noé del escritor colombiano Guillermo Bustamante Zamudio, se intenta parodiar el discurso jurídico para interpelar los procesos comprensivos implicados en la lectura minificcional y con ello, develar temas, estrategias y significados. El propósito es comprender todo el circuito hermenéutico que le permite al lector arribar a posibles juicios en torno a las coordenadas de universo sostenido en la desacralización, el carácter subversivo y la producción de tensiones narrativas que se debaten entre el absurdo, la incertidumbre y lo lúdico como síntomas de un texto siempre limítrofe e inestable. Para el tratamiento de estos aspectos, se recurre a una comprensión hermenéutica y una aproximación fenomenológica sustentadas en los planteamientos de Piglia y Guillén. Como resultado, tenemos un texto enjuiciado alrededor de la caída de todas las certezas, lo que deviene en el ejercicio de una lectura detectivesca llena de acertijos, sospechas y persecuciones.

Palabras clave: minificción, lectura, juicio, desacralización y hermenéutica

\begin{abstract}
Regarding the mini-text Divine Justice belonging to the book Oficios de Noé by the Colombian writer Guillermo Bustamante Zamudio, an attempt is made to parody the legal discourse in order to question the comprehensive processes involved in the mini-fiction reading and thereby reveal themes, strategies and meanings. The purpose is to understand the entire hermeneutical circuit that allows the reader to arrive at possible judgments about the coordinates of the universe sustained in the desacralization, the subversive character and the production of narrative tensions that are debated between the absurd, the uncertainty and the playful as symptoms of an always borderline and unstable text. For the treatment of these aspects, a hermeneutical understanding and a phenomenological approach are used based on the proposals of Piglia and Guillén. As results we have a text judged around the fall of all certainties, which becomes the exercise of a detective reading full of riddles, suspicions and persecutions.
\end{abstract}


Keywords: minifiction, reading, judgment, desacralization and hermeneutics

Recibido: 12 de octubre de 2020 - Aceptado: 16 de diciembre de 2020

\section{Juicio: parte expositiva. Buscar pistas en el texto minificcional}

La lectura del texto minificcional, dada la economía lingüística, de recursos y dilaciones narrativas, proyecta genuinos desafíos para su comprensión y significación. Y es que, el lector no solo (re) construye las pistas del texto para darle forma al mundo posible que es (re) creado, sino que debe posicionarse ante un abismo de sentidos y un laberinto de significados. Pues, en compensación a esas cortas líneas y a esos escasos elementos, ahora surge un despliegue de infinitas posibilidades de lectura que tienden a propiciar alternabilidad de opciones para comprender y multiplicidad de versiones para interpretar.

Se entiende que, en paralelo a los compromisos demarcados por la lectura del texto minificcional, le advienen los desafíos propios de un ejercicio lector consustanciado con un tránsito investigativo del cual germina toda posibilidad de juicio, entendido como adjudicación de sentido y establecimiento de significados. De este modo, el lector: se posicionará en el universo minificcional, establecerá los diálogos posibles del hecho (re) escritural, materializará la autonomía o unidad del fragmento narrativo y generará nociones para desplazarse por el cruce genérico, la emergencia de recursos o el laberinto de experimentaciones.
Junto a este compromiso, ahora ese lector - investigador, asumirá un recorrido de lectura que fluctúa entre categorías conceptuales (siempre en tensión y ruptura) y el carácter procesual de la estructura narrativa (siempre subversiva y en límite). En este trayecto de márgenes hermenéuticos y fenomenológicos expresados en la estética de la recepción, circula la comprensión einterpretación del texto minificcional. Visto así, no solo interesa observar la articulación del complejo teórico con los productos literarios, sino examinar la apuesta del horizonte epistémico con las construcciones derivadas del ejercicio investigativo implicado. Parece que estamos frente a una lectura que se hace metaliteraria, no porque el mensaje se centre en sí mismo, sino porque la significación vuelve una y otra vez, al examen de ese minúsculo universo para buscar pistas (o algunas certezas) que hagan posible su comprensión. Una escena del crimen revisitada regularmente para tratar de encontrar algo. Desafortunadamente, cada nueva visita trae consigo inéditos indicios para incriminar o absolver a un único sospechoso: un texto indómito, (des) generado y fragmentario.

En este aspecto, es importante advertir que tanto la lectura asumida y, por ende, el trayecto investigativo recorrido, son abiertos e inacabados. Es decir, no solo establecen puentes articulatorios con la obra, el trabajo estético del escritor y los discursos críticos y teóricos; además el esfuerzo 
se orienta a develar otros sentidos, rutas investigativas y exploraciones estéticas. Sin embargo, no todo está dicho, y propio del texto minificcional, la lectura asume unas dimensiones de completitud con otras indagaciones, realimentación desde diversas miradas críticas, apertura al presente y al devenir de la obra como expresión fragmentaria; $\mathrm{y}$, multiplicidad en tanto búsqueda, comprensión y significación, lo que milita con una mirada aproximativa, dinámica, abierta e inacabada hacia la interpretación como una actividad inherente al propio ejercicio indagatorio (o detectivesco) implicado en ese abismo en miniatura.

Para sustentar este ejercicio de lectura, resultan a propósito los aportes de Ricardo Piglia y las lúcidas observaciones de Claudio Guillén. Nos dice el autor de Respiración artificial que en todo relato hay siempre dos historias, la visible y la secreta, y que es tarea del lector advertir la secreta (Piglia, 1986: 65). Para ir dimensionando estas perspectivas teóricas, se recurrirá al examen de la obra Oficios de Noé y a otras producciones literarias del escritor colombiano Guillermo Bustamante Zamudio. En el caso de Oficios de Noé, es un texto compuesto por un conjunto de piezas minificcionales que se articulan alrededor de las aventuras del mítico personaje. En esta obra, la historia aparente es la reescritura mítica; por su parte, la secreta se balancea entre el propio cuestionamiento de la credulidad y la angustia ante el vacío al que fue arrojado el hombre. La parodia, ironía, humor y juego son el velo de una profunda reflexión filosófica cargada de humanismo, actualidad y desencanto. Veamos:

\section{Sustantivo}

El arca se atascó en el monte Ararat. Seabrió la compuerta y descendieron las parejas de animales, una a una, en lenta procesión. Luego bajaron, en orden jerárquico, Noé y esposa, Sem y esposa, Cam y esposa, Jafet y esposa. Dios contemplaba todo aquello con satisfacción. Pero, de pronto, se oyó venir de dentro una multitud desordenaday empezaron a bajar el ladrón, el listo, la prostituta, el delator, el inquieto, el acreedor, el ruin, el ordinario, el coqueto, el cobarde, el transportador de droga, la fea, el irascible... la multitud no parecía tener fin.

—PPor mí, Noé! ¿Qué es todo esto? - exclamó Yavé-. Tus instrucciones eran claras. -Me dijiste que hiciera entrar al arca parejas de animales...

-Pero estos no son animales...

-Sí que lo son, mira: aquél que huye hacia allá es una rata; éste con gesto calculador es un zorro; aquélla que apoya un tacón contra la pared mientras fumando espera es una perra; el que se ve ahí, susurrándole a otro, es un sapo; ¿ves el que no para de moverse?, es un mico; el del portafolio es una culebra; este que no camina, sino que se arrastra cobardemente, es una sabandija...

-Ay, Noé...

-Espera, ¿le ves los modales a ése?, jes un cerdo!; aquel otro que quiere estar con todas es un picaflor; mira ese que trata de ocultarse, es un gallina; ahora repara en ése: estuvo inquieto durante todo el viaje y ahora se tiene el estómago... te aseguro que es una mula; esa mujer horrible, perdóname, Señor, 
es un bagre; aquél, dispuesto a pelearse con quien sea, es un gallito...

-Ay, Noé, por no distinguir entre un adjetivo y un sustantivo, dejaste todo como al comienzo (Bustamante, 2005: 27).

La burla no solo es a los grandes relatos, las formas genéricas o la tradición literaria, tampoco se concentra solo en un espíritu de ruptura, límite o subversión; la gran burla es hacia el discurso de la fe, hacia la soledad del hombre, hacia la falta de proyecto espiritual; en fin, hacia ese terreno de creencias sostenido en lo incierto, paradójico, absurdo y muchas veces, irracional. De la parodia, nos dice Piglia lo siguiente:

[...] ciertas corrientes actuales de la crítica buscan en la parodia, en la intertextualidad, justamente un desvío para desocializar la literatura, verla como un simple juego de textos que se autorepresentan y se vinculan especularmente unos a otros. Lo básico para mí es que esa relación con los otros textos, con los textos de otro que el escritor usa en su escritura, esa relación con la literatura ya escrita que funciona como condición de producción está cruzada y determinada por las relaciones de propiedad [...] (Piglia, 1986: 53).

Este autor reitera el llamado de relación social que sustenta el hecho literario, por ello ante el "desvío para desocializar", el autor corrobora que la intertextualidad y la parodia vienen a ser modos de apropiación que legitiman el carácter socializador que determina y sustenta el estatuto de lo literario (Piglia, 1986: p. 54). No solo es el sistema de burlas que se tejen en Oficios de Noé lo que podría atraer el análisis, interesa además ver cómo Bustamante Zamudio aborda la noción de transformación alrededor de conceptos que se desplazan por el texto y desde esa circulación, intentan explicar la realidad. Por ejemplo, el fallido proyecto de unidad que plantea la obra (es fallido en tanto autonomía del fragmento narrativo que es básicamente el postulado implícito) es también la exploración ideológica signada por la ruptura, el quiebre y la desarticulación. De esta forma, como se está viviendo, es construido el texto y así también es leído el mundo. Otro ejemplo sería la reescritura, y es que la historia de Noé ampliamente socializada desvanece la idea de propiedad para refundarse en el esta mento de apropiación; es decir, la gran historia ahora tiene los matices que le dio el escritor. Ya el pacto de autoría queda disuelto, lo que genera nuevos códigos de lectura y así, funda dos nuevas tensiones conceptuales: lo social se hace privado y viceversa; y, lo instalado es parodiado para suscitar entonces la renovación.

Desde las lúcidas observaciones del autor de Crítica y ficción (1986), podemos advertir algunas tesis fundamentales que se vehiculan con la significación posible y que vienen a ser tributarias del texto minificcional: a) la lectura siempre discurre en ese anhelo de encontrar las pistas precisas para encarcelar al criminal, así b) el lector, es además un investigador, un detective, el escritor es un delincuente, un criminal. Este planteamiento es de vital importancia en el tratamiento de textos minificcionales que descansan en un esfuerzo reescritural. De esta forma, c) encontrar pistas implicaría atribuir diversos sentidos a la lectura, descubrir el plagio enmascarado en la relación 
intertextual y develar las trampas que se han ido postulando al lector hasta llegar a despejar o complejizar suposiciones y sospechas El resultado de toda esta persecución vertiginosa, desconcertante y paranoica es el enfrentamiento con realidades también desconcertantes, ilusorias, sorprendentes, caóticas y absurdas. Visto así, d) la sospecha suscita amplitud tanto en la mirada de los textos como en las perspectivas teóricas y críticas, consumando un análisis en el que circula lo literario en relación abierta con lo social y cultural (Piglia, 1986: 50-60). El autor advierte:

[...] Me interesa mucho la estructura del relato como investigación: de hecho, es la forma que he usado en Respiración Artificial. Hay como una investigación exasperada que funciona en todos los planos del texto [...] el investigador se lanza, ciegamente, al encuentro de los hechos, se deja llevar por los acontecimientos y su investigación produce fatalmente nuevos crímenes; una cadena de acontecimientos cuyo efecto es el descubrimiento, el desciframiento [...] (Piglia, 1986: 48).

\section{Desacralización: parte considerativa}

Al soporte teórico de las rutas de lectura asumidas en este desafío investigativo, se sumarían los aportes de Claudio Guillén organizados desde las siguientes construcciones epistémicas.

Leer una obra que ha sido el producto de un ejercicio reescritural se sustenta siempre en la noción de actualización. No solo se actualiza el horizonte de expectativas que asumió el lector-escritor en torno al hipotexto para producir la reescritura, también se actualiza el texto reescrito a partir de los horizontes que despliega la nueva experiencia de lectura, solo que en esta oportunidad, la actualización se desplaza en una triple perspectiva: del hipotexto al texto reescrito como ejercicio de producción (qué actualizó Bustamante Zamudio del relato bíblico en Oficios de Noé), del texto reescrito a nuevos horizontes desplegados por la recepción (qué actualización despliega el lector a partir de Oficios de Noé); y, de los sentidos del hipotexto a los de la reescritura vistos en perspectiva a partir de la emergencia de la actividad comprensiva e interpretativa (qué actualización se despliega de los sentidos atribuidos a la reescritura en diálogo tanto con su hipotexto y como con las nuevas posibilidades de significarlo y escribirlo). Este tránsito diluye las nociones de propiedad y ahora en todas estas transiciones se demanda una instancia de co- producción. Dimensionemos estos planteamientos en el abordaje comprensivo del siguiente texto tomado del libro Oficios de Noé:

\section{Justicia divina}

Después del diluvio, una vez repoblada la tierra, Dios comprendió que entre los hombres seguían existiendo el bien y el mal. Molesto por la ineficacia de una acción tan onerosa y pretendidamente ejemplar, mandó a su ángel justiciero -espada flamígera en mano- a separar, de una vez por todas, el bien del mal.

Esta medida, que no anunciaba -como la anterior- el exterminio del hombre, si lo logró, pues cada ser humano quedó partido en dos (Bustamante, 2005: 56). 
Bustamante Zamudio libera una zona del mito (qué ocurrió luego del diluvio y cómo logra Dios erradicar definitivamente el mal). Desde una lectura abierta, aproximativa e inacabada, el lector actualiza la idea de exterminio (los hombres quedan simbólicamente partidos en dos). Esta tríada se completa cuando el lector enlaza el hipotexto con la reescritura y advierte la elección de dos ideas: o se acepta que el bien y el mal son parte constitutivas del hombre o, se asume que para erradicar el mal será necesario exterminar al hombre. Como se puede observar es una lectura llena de múltiples significados, de infinitas posibilidades de permuta y de insospechadas rutas para la alternabilidad, elección y relativización. El ejercicio de lectura es influenciado por estas rutas hermenéuticas (actualización, renovación, variación); por su parte, el desafío hermenéutico es afectado por los compromisos de lectura (enciclopedia, contexto, transformación). Esta recursividad afecta tanto al ejercicio comprensivo de la lectura como a la atribución de sentidos y significados que despliegan los horizontes interpretativos. Nos dice Guillén lo siguiente:

Una sucesión de producciones y de recepciones, de obras producidas, leídas y releídas, compone los eslabones de esta relación constante, siempre renovada, entre las obras y los receptores. [...] Hay una conexión cambiante y sucesiva entre lectura y horizonte que afecta y modifica a los dos (Guillén, 1985: 364).

La elección de rutas para transitar lo serial, reescritural y minificcional distinguiría tres desafíos para atribuir sentidos: a) la obra como instancia dada no está terminada pues, además de vacíos, tiene espacios para la permuta y el juego; b) la obra surge como una entre las tantas posibilidades de contarla y su comprensión es el resultado de una entre las tantas perspectivas de significarla, lo que implica el poder del texto para crear mundos posibles y el poder de la lectura para desarrollar niveles de conciencia traducidos en múltiples horizontes interpretativos; y c) el texto exige la participación del lector en la co-producción de sentidos lo que se entiende como la posibilidad estética de que ambos mundos (el del texto y el del lector, y quizá hasta el del autor) se estrechen en el proceso de reactualización, recreación y resignificación. Ejemplifiquemos este interés conceptual con un texto minificcional extraído ahora del libro Convicciones y otras debilidades mentales de Guillermo Bustamante Zamudio:

\section{Requisición}

Los agentes de inmigración requisan minuciosamente su equipaje. Buscan droga. Él se encuentra nervioso, trata de evitarlo, se contiene con todas sus fuerzas, no puede más: -iHaschisch!

Lo toman preso (Bustamante, 2002: 50).

Hay varias formas de interpretar un detalle del texto, por ejemplo, el estornudo. Su transcripción onomatopéyica podría leerse como una aproximación fonética al nombre de un tipo de droga que se devela en el acto de la requisición; sin embargo, otra opción haría emerger algunas interrogantes: ¿acaso es un síntoma de nerviosismo o acaso por la fuerza, el requisado expulsa o deja en evidencia aquello que lo incrimina? No sabemos qué ha ocurrido, la única certeza es que ha sido apresado. 
Este es el punto neurálgico en la minificción, un texto sin certezas que atrapa y desconcierta, un delicioso fragmento de extravío, vacilación y confusión. Vemos cómo operan esas trampas del juego en el establecimiento de infinitas hipótesis de lectura; si bien el autor ha optado por una forma de contarla, el ejercicio de co-producción asumido desde la lectura, puede desplegar múltiples perspectivas para interpretarla. De allí que la actividad del lector sea decisiva para estrechar los mundos puestos en circulación tanto a la hora de enfrentar el pequeño texto al propio equipaje de recepción, como al momento de resignificar el abismo en miniatura. Para Guillén:

La distancia estética se debe a la dimensión que distingue el mundo del lector del de la obra que lee, concebida no como simple reflejo de lo dado y existente [...] sino como proceso formador de realidades y de niveles de conciencia [...] la actividad del escritor [...] fundamenta un proceso de comunicación, un argumento en que él mismo ya no interviene y cuyo desenlace está en manos de sus lectores (Guillén, 1985: 364-366).

El sentido final de la comprensión apunta a superar el pasado de la creación por el presente de la recepción. En este sentido, lo que priva no es un interés histórico alrededor de los núcleos temáticos, sino una preocupación de doble ejercicio: la relación histórica que se despliega del ámbito comunicativo derivado de la lectura y, el ámbito histórico que alimenta, estrecha y separa el contexto de producción y de recepción, visto en devenir a través de la experiencia (de la lectura) y el horizonte (de expectativas). El texto (pasado en su producción) se va reescribiendo (se va actualizando en su recepción) en el tránsito de una lectura que diluye las distancias temporales y también espaciales. Los contextos se nutren y actualizan y así los referentes van moldeándose de acuerdo con las expectativas que ahora el propio texto se ha formulado de su lector potencial. Veamos dos textos que, como sus nombres lo indican, se corresponden con una seguidilla (propuesta progresiva de ir construyendo un texto minificcional adicionándole material con otro nuevo texto) compendiada en el libro Disposiciones y virtudes de Bustamante Zamudio:

\section{Seguidilla cartesiana I}

Dios proveyó al hombre de un juicio desmañado e inestable, susceptible de ser influido por opiniones falsas e irracionales. Por eso pudo creer en Dios.

\section{Seguidilla cartesiana II}

Dios proveyó al hombre de un juicio desmañado e inestable, susceptible de ser influido por opiniones falsas e irracionales. Por eso no demoraron mucho los necios en desmentir la única certeza bien fundada que tenía el hombre: la existencia de Dios (Bustamante, 2016: 101-102).

La dicotomía entre creer en Dios por el establecimiento de un juicio afectado por lo falso e irracional y no creer a causa del mismo juicio no solo nos lleva a advertir como el texto hace o deshace la existencia de Dios. Este texto une en un mismo punto al acontecimiento mítico que se asume ya 
acaecido con el presente de una recepción que se reactualiza desde las demandas del contexto actual. No es una cuestión semántica, está más bien referida al conjunto de sentidos siempre distintos que es capaz de desplegar infinitamente el texto, lo cual diluye la historicidad en el proceso de lectura; sin embargo, la reitera desde el carácter enciclopédico que se hace necesario para lograr la comprensión. En este cruce contradictorio surge la duda ya no como eje temático del texto, sino como sustento de la coproducción, aliento de la significación y ausencia de límite en la noción de contexto. De esta forma, la recepción se irá haciendo nítida solo desde los márgenes de actualización que demarque la experiencia de lectura, esto es la expresión auténtica de su presente, y, por ende, de su eterna vigencia. En palabras de Guillén:

[...] una decidida comprensión del abismo hermenéutico que separa aquel pasado de su propio presente [...] dibuja la historia de la recepción, que es al propio tiempo un proceso pretérito sobre la marcha [...] y la captación de ese proceso desde la diferencia ineluctable, funcional y prioritaria del presente (Guillén, 1985: 364).

La comprensión cumple una función socializadora, no solo por el acto comunicativo que condensa o por el diálogo enciclopédico e intertextual que suscita, sino por la posibilidad de estrechar el significado de las rutas interpretativas a la cotidianidad circundante. Estamos en presencia de una actualización de los contextos de lectura que permiten atribuirle un sentido al texto desde su vínculo con la vida cotidiana. De esta forma, leemos desde un contexto y comprendemos desde la posibilidad de diálogo que es capaz de desplegar el texto con éste. Es allí donde adjudicamos sentidos, elegimos perspectivas y movilizamos reflexiones, afectos e intereses. Acerquémonos al siguiente texto tomado del libro Roles de Guillermo Bustamante Zamudio:

\section{El usuario}

Creado el teléfono celular, la dificultad del vínculo con el semejante por fin parecía ceder: si no eras capaz de hablarlo de frente, podías hacerlo a través del portátil. Pero la dificultad porfiaba: qué decir por el aparato, cómo decirlo. Entonces se agregó el botón de mensajes para toda ocasión: ¿te atrae y te da pena confesarlo?, ¿atraviesan por un disgusto?, ¿palabras para una fecha significativa?, ¿necesitas una buena excusa?... Para toda ocasión, la máquina- que aprendía el timbre singular de tu pronunciación-formulaba las palabras adecuadas. Y eran tan adecuadas que muchas veces el destinatario, aun sin ser propiamente tímido, se sentía sobrepasado. Por eso, también se inventó el servicio de respuesta: si vacilabas para contestar, si no encontrabas la expresión justa, el aparato hacía lo pertinente, usando tu propia voz. Viendo que sus teléfonos sí parecían comunicarse fácilmente, los usuarios empezaron a charlar cada vez menos, mientras los aparatos se dedicaron a dialogar entre ellos. Ahora los usuarios escuchan en secreto esas conversaciones, cada vez más alejadas del alcance que ellos mismos tendrían 
si pudieran dar rienda suelta a lo deseado (Bustamante, 2007: 141).

El texto dialoga con la cotidianidad circundante, comprenderlo implica necesariamente ponerlo en diálogo con la realidad. No se trata solo de que su temática estálegitimada desde las circunstancias que bordean al hombre de hoy, antes bien implica dimensionar sus tres complejos temáticos (el fenómeno de la telefonía celular, la paradójica incomunicación del hombre y la tecnología como dilución y desplazamiento de lo humano) desdeuna ruta enciclopédica que concretiza el contexto de lectura, capaz de desplegar los sentidos del texto a partir de las transiciones de correspondencia y relación con la vida cotidiana. A propósito, resultan los aportes de Guillén quien plantea que: " $\mathrm{La}$ función social de la literatura se cumple después, una y otra vez, constantemente, cuando la lectura alcanza y penetra el horizonte de expectativas de la vida cotidiana del hombre, afectando su sensibilidad y comportamiento" (Guillén, 1985: 367).

El siguiente esquema, sintetiza el ejercicio hermenéutico seguido para el abordaje de los textos en este desafío lector e indagatorio. Si bien para Piglia (1986) el acto de lectura del cuento implica advertir la historia visible y la historia secreta que constituye al texto. Para Guillén (1985), la comprensión parte de la relación entre lo uno y lo diverso; es decir, desde la especificidad de nuestro objeto de estudio, sería comprender el fragmento minificcional y a partir de sus propias tensiones, coordenadas y propuestas, reconocer (en transiciones dialógicas) la multiplicidad de lecturas, significados y sentidos que de él deriven.

Observemos el siguiente cuadro que sintetiza los planteamientos, articulándolos en una dimensión complementaria, la cual permite fundamentar la experiencia hermenéutica que circula tanto en la aproximación al texto minificcional como en las transiciones inherentes al proceso indagatorio de pistas que vislumbren posibles sentidos y significados.

\section{Imagen 1: Transiciones hermenéuticas implica- das en la lectura del texto minificcional}

Fuente: Elaboración propia del autor, 2020.

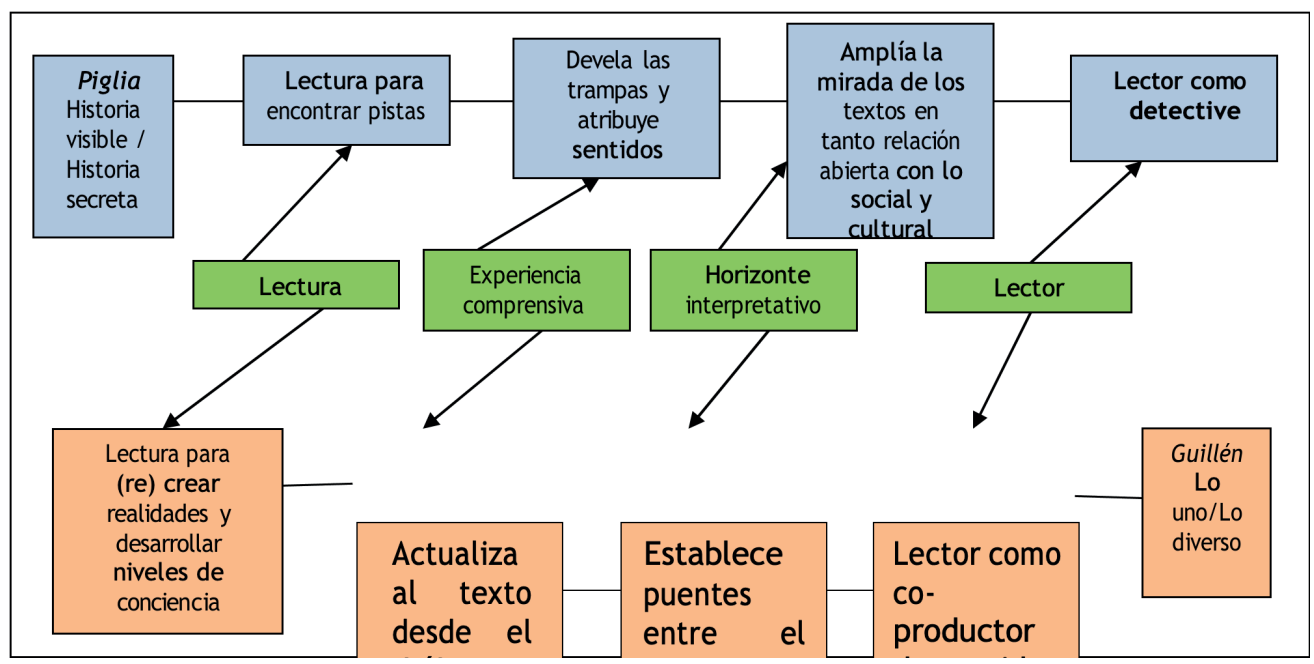




\section{Ratio decidendi: indicios para un fallo conde- natorio. Lecturas y extravíos en Oficios de Noé de Guillermo Bustamante Zamudio. Algunos ejercicios}

Ya se ha observado en la obra de Guillermo Bustamante Zamudioy, específicamente, en Oficios de Noé, el examen de tres grandes construcciones discursivas: la reescritura, la escritura serial y el universo minificcional. Rescatemos ahora tres dimensiones temáticas que cohesionan la aspiración estética de nuestro escritor y fluyen por las vertientes estéticas de su propuesta minificcional, a saber: a) la duda existencial, la tensión moral y el cuestionamiento religioso; b) la preocupación por ámbitos psicológicos complejizados desde el lenguaje, la razón y el pensamiento como actos de rebeldía; y, c) la militancia social, el desplazamiento del individuo por la noción de masa y las caóticas relaciones de poder, cuya emergencia suscita el movimiento social. Estos temas fluyen en su escritura, se funden en un denso bloque temático y materializan la preocupación crítica y reflexiva de Bustamante Zamudio. Solo para fines didácticos, estudiaremos algunos ejemplos representativos de cada dimensión; sin embargo, en un solo texto puede operar todo un conjunto de elementos que complejizan la arquitectura del abismo minificcional y pueden ser dimensionados a partir de diversos lugares de lectura.

En cuanto a la preocupación por aquellos aspectos metafísicosy de la existencia: duda, incertidumbre y angustia por el devenir humano; Bustamante Zamudio a través del velo minificcional, construye una relación compleja que hace más denso el abismo, su misión permanentemente es reflexionar, criticar y cuestionar. Así, el fragmento narrativo es solo un pretexto que establece permanentes puentes con problemas filosóficos, sociales y psicológicos. Esto no es extraño en el universo minificcional, de allí sus amplias posibilidades de lectura; sin embargo, lo interesante de la propuesta estética de nuestro autor es ese asedio constante a la herencia religiosa, el incisivo abordaje a una moral que en cada trazo escritural se hace más inestable, en fin, esa mirada de aparente indiferencia a ese vacío en el cual, inexorablemente, descansa el proyecto humano. Detengámonos en el "cuestionamiento a la herencia religiosa”.

En Pares y nones el proyecto divino legitima la infidelidad. Los animales, al ser escogidos por el azar, repudian que sus nuevas relaciones vendrían a destruir sus uniones establecidas. Visto desde la animalidad, el autor nos hace advertir que la vergüenza al adulterio la padecen los animales y no el creador; por consiguiente, aunque el pensamiento superó al llamado instintivo, los animales en su docilidad (por obediencia simple) y pese a su carácter dubitativo, pudieron ser felices; sin embargo, los humanos, a los que sí se les respetó su unión establecida, no fueron felices, no pudieron superar sus propias dudas y vieron frustrados los deseos escondidos de su corazón: quizá las ganas de una infidelidad forzosa para superar el hastío de una costumbre llena de desencantos y cuestionamientos. Ya en El viaje, se nos muestra cómo la injusta ofrenda del sacrificio acaba con algunos especímenes. El rito inexplicable pone en tensión la justicia, el razonamiento y la consistencia del proyecto divino. 


\section{Pares y nones}

Con su propio linaje, Noé salvaría a los hombres respetuosos de Dios. Y para salvar a los inocentes animales, introduciría al arca parejas de aves del cielo, ganados, bestias y reptiles terrestres.

Ahora bien, los machos y las hembras escogidos casi nunca estaban ligados de antemano; en muchos casos, su unión habría sido imposible mediante el encuentro entre las hormonas y los órganos que las saborean; la elección casi siempre pasó por deshacer parejas ya conformadas. Pero nada de esto fue inconveniente: los animales, respetuosos e ignorantes de la condición impuesta, no sintieron el llamado instintivo hasta ser liberados bajo el mandato de crecer y multiplicarse. Entonces cumplieron, también dóciles, con la desvergüenza a la que tal consigna llamaba.

Por su parte, Noé y esposa ya eran una pareja, decisión respetada, aunque cada uno se preguntó si habría sido afortunado de haberle correspondido otra. Llamados a mantenerse castos durante el viaje, musitaban plegarias y rumiaban pensamientos, pero estos remedios no conseguían atenuar la duda, sino fortalecerla. Ambos también fueron exhortados a crecer y multiplicarse, a poblar la tierra; pero finalmente no pudieron, y esa misión debieron asumirla los hijos engendrados antes.

Los animales, que no tenían razones, aceptaron cada impedimento, obraron en consecuencia, fueron felices. Noé y esposa, que podían fabricar explicaciones, no atinaron, sufrieron, dudaron, fueron infelices (Bustamante, 2005: 11).

En el texto Generación perdida, el cuestionamiento apunta hacia el proyecto incestuoso en el cual descansaría la refundación del universo. Algunas ideas confrontadas desde los planteamientos del mismo texto vienen a cuestionar al relato sagrado, de allí que entran en tensión las siguientes ideas: a) Noé no podía ser el único bueno, pues alguien debió haber modelado su conducta; b) gracias a la acción de los hombres, la especie humana pudo pervivir; y c) en virtud de que otros también se salvaron es que pudo evitarse la multiplicación a través del incesto. Lo que triunfa entonces no es el ideal divino sino el humano que parecía ser más coherente con la aspiración de un mundo nuevo. Finalmente, en Incomunicación, evidenciamos un sostenido empeño de negación del proyecto cristiano: Dios no es la única deidad existente, su rasgo distintivo es la ira y su existencia descansa en la decisión de creer. Este texto condensa una crítica al estilo de Nietzsche, Dios ha abandonado al hombre, por lo tanto, no hay ninguna intención divina de castigar y mejorar el mundo, tampoco hay alianzas con la humanidad. Esta tesis angustiosamente persigue a nuestro autor: el hombre ha sido arrojado al mundo y está solo, entonces todo esto ha sido inventado por la necesidad de creer.

\section{Incomunicación}

Un hombre se siente escogido. Eso es normal. Cree que el dios habla con él, delira un diluvio y procede en consecuencia. Eso ya es anormal. Pero, de pronto, efectivamente se desencadena un muro de agua. Eso es 
una feliz coincidencia para él, aunque él y quienes no vivieron para recordarlo hayan creído que sus palabras eran proféticas. En cualquier caso, la realidad no prueba nada. Creemos que un dios - o su ira- está en la caída despiadada del agua, aunque habita en igual proporción en cada pequeño dolor de los sobrevivientes. Creemos que un dios —o su paz- está en el resplandor posterior al descenso de las aguas, aunque habita en igual proporción en el gusto elemental de la fruta renacida.

Los dioses no saben de medidas, son todopoderosos. No hablan con los hombres, no les interesan sus humanos destinos(Bustamante, 2005: 44).

Para ilustrar el cuestionamiento moral, revisemos algunos textos. Delegatario descansa en la dicotomía entre un Dios que se arrepiente y cumple sus promesas frente a un hombre que es orgulloso y soberbio. Esto hace que el creador, dada la conducta humana, busque una forma de disolver el pacto a través de los vicios del propio hombre. De esta forma, no resulta extraño que el hombre, actuando en nombre de Dios, asole la tierra con la guerra. Hay aquí una doble moral pues Dios cumple su alianza con la humanidad; sin embargo, para continuar el exterminio de la carne, invoca al hombre. La máscara quizá oculta la delegación que el creador ha sembrado en su criatura para erradicar cualquier intento de pacto. La blasfemia sustenta, al igual que a este texto, a todo el universo minificcional de Bustamante Zamudio y, desde ese aparente descrédito, la burla trasciende a la preocupación, la negación al desconcierto y la racionalidad a la duda. El castigo podría ser inminente... ¿y si todo termina siendo cierto?

En Calla mientras, sobrevivir al diluvio no fue un premio. Lo que se vivió en el arca durantela lluvia, hizo brotar un sentimiento de rebeldía, repudio y blasfemia que se igualaba precisamente, con la conducta y los vicios que habían sido castigados. La tensión moral llega al clímax cuando Noé se pregunta alrededor de los atributos y convicciones con los que cuenta para poblar la tierra, dado que el resentimiento, lo sanguinario y la inmoralidad se habían alojado ahora en su espíritu. Ya no agradece a su creador, obedece al mandato de comer carne y por primera vez se embriaga. Esta conducta inédita auguraba el inicio de una nueva vida tanto para Noé, como para las venideras generaciones.

La serpiente es un texto que ilustra cómo el aparente mal oculta la verdad, pues con el llamado a abrir los ojos, se intenta que el hombre devele la mentira que ocultan las palabras del creador, descubra el proyecto divino como una fórmula para el castigo perenne y asuma con valor el cuestionamiento Se instaura una crítica a las formas de modelización y a la hegemonía del poder, pues con la destrucción de la serpiente se deduce que todo aquél que desmienta, refute o desobedezca al Señor será erradicado, quizá porque en el fondo, la blasfemia oculta vestigios de verdad - preocupación, por demás recurrente en nuestro autor.

\section{La serpiente}

—De todos los seres vivientes meterás contigo en el arca dos individuos de cada 
especie, macho y hembra, para que se salven contigo —ordenó Yavé.

Noé se puso en ello y todo iba bien, hasta toparse con la serpiente.

—Ey, suéltame! ¿Qué haces? —exclamó la serpiente.

Noé le resumió la historia, y la serpiente respondió tranquilamente:

-No es cierto, no habrá diluvio.

-Y lo dices con ese desparpajo...

-Fui yo quien le dijo a Eva que no era cierto que morirían si comían delárbol situado en medio del jardín.

—Ajá! ¡Tú...!

— ¿Y acaso murieron tus parientes? —interrogó la serpiente.

-Pues... no...

-Ocurrió, más bien, lo dicho por mí: se abrirían sus ojos, y conocerían el bien y el mal. Sencillamente, Yavé tramaba otra cosa: la expulsión del paraíso, la protección del árbol de la vida con el fin de evitar a tus bisabuelos vivir para siempre.

-... y si mal no recuerdo eso te costó ser maldita entre todas las bestias y arrastrarte sobre tu vientre.

-No. De esa forma fui siempre. ¿O crees que antes del insuceso yo tenía patas? ¡Soy una serpiente! Con conocimiento de causa, te lo digo: no habrá diluvio.

- Te dará igual si no te escojo para ser introducida en el arca...

- ¡Pues claro! Te acabo de dar pruebas, hombre, ipru-e-bas! Sigue con tu necia labor y déjame fuera.

Efectivamente, de esta especie de serpiente no hubo en el arca. Y así, luego del diluvio, ningún ser volvió a tener el valor de fiscalizar las acciones del Señor (Bustamante, 2005: 35).

Dos textos adicionales podrían profundizar el abordaje de la moralidad. En Orden parece que Dios inventa el pecado para justificar el castigo, y éste como fórmula para alcanzar el orden, pues en el fondo el interés de aleccionar al hombre no es más que un mecanismo para que Noé organizara la refundación del universo y en la organización de los animales el creador sintiera complacencia. Ya en Cosas de mujeres la tensión moral vuelve a poner sus ojos en tres aspectos: la mujer hace pecar al hombre y lo incita a la desobediencia, la duda introduce el miedo a la traición; finalmente, Noé no arribó al arca, vivió la muerte y por esa razón Dios debió inventar nuevos hombres. Observamos cómo se teje un trasfondo de conveniencias, sospechas y alianzas que desestabilizan la moralidad del creador y su criatura alrededor de la falsedad y maldad solapada.

\section{Cosa de mujeres}

-Yavé es mi aliado: me va a salvar de algo peor que lo imaginado por la ira de un enemigo - comentó Noé a su esposa.

-Tienes un amigo poderoso... pero, ¿cómo vas a equipararlo?, ¿qué puedes darle que Él ya no tenga, que no pueda procurarse por sus propios medios?

-Es cierto. Si no puedo favorecerlo, ¿por qué su consideración conmigo?

-Con seguridad no se trata de amistad; tal vez te precisa para realizar su furia — sugirió 
ella-. Si Yavé no es tu amigo y hoy te salva, igual mañana serás objeto de sus desmanes. -A todos les va a ocurrir algo impensable, pero conmigo podría redoblar esa magnitud... Tienes razón. Prefiero morir ahora, con todos, y no mañana solitario, donde ni siquiera tenga sentido gritar.

Con ello, la mujer había hecho desobedecer al hombre por segunda vez. Noé introdujo al arca parejas de animales y cerró. Se escondió con su familia y contempló cómo el arca, donde Dios suponía que se hallaba la semilla del hombre, empezaba a flotar vacilante. Noé compartió la esperanza con los hombres en los montes más altos; sufrió el temor; vivió la muerte.

Nadie sabe cómo eran esos hombres. Se dice que duraban hasta 900 años. Los de hoy descienden de otros que debió inventar Dios (Bustamante, 2005: 63).

Recurrentes, en Oficios de Noé, son las preocupaciones existenciales. En Mientras calla con la cláusula "El todo no puede formarse sin al menos un elemento dejado por fuera" (Bustamante, 2005: p. 60), se reflexiona en torno a la culpa que siente Noé por ser el argumento del exterminio (dada su conducta ejemplar) y la evidencia del comportamiento divino (solo él sobrevive). En este texto la imagen de Noé como referencia, resulta fundamental para testimoniar las razones del exterminio y la cólera del creador. Por ello, nuestro personaje se asume como un instrumento de comparación que viene a justificar todas las connotaciones del castigo divino. El remordimiento, cuestionamiento lógico e infeliz curso de la existencia humana (asediada permanentemente, por la desobediencia, el razonamiento y la culpa) vienen a ser la huella de una relación caótica entre Dios y los hombres, angustia constante en los laberintos escriturales de Bustamante Zamudio.

En El todo de las partes Dios observa que la nueva generación salió idéntica a aquella que fue sacrificada y en consecuencia entiende que bien y mal son partes constitutivas de la condición humana. En este sentido, la materia supera la espiritualidad y en ella resuena una dualidad inextricable que se escapa, incluso, a los designios de la voluntad divina. Pero no solo de esta dualidad está constituido el hombre, también lo está de una materia temporal. Al hombre siempre le preocupa el tiempo no por las huellas de su paso, sino por la proximidad con lo desconocido, por la marcha de su devenir. Este es el planteamiento del texto Materialidad, la preocupación aquí es el conflicto del tiempo, tanto por su paso, como por la memoria que intenta atraparlo. La preocupación por lo desconocido, la necesidad de saber o reinventarse un origen y un destino, el pecado que implica el saber o la búsqueda de explicaciones y la incesante lucha entre fe y razón son material para este abismo minificcional en el cual triunfa la parálisis ante el desconcierto y la incertidumbre reinante.

\section{El todo de las partes}

El bien y el mal eran uno. Cuando se creó el mundo material, el bien quedó del lado de Dios inmaculado, y el mal del lado de la materia y sus providencias. Aparecieron los hombres, forjados a semejanza de la nueva imagen: de espíritu y de materia: de bien y 
de mal. Sus acciones pronto hicieron titubear a Dios, quien decidió sepultarlos bajo el furor de las aguas diluviales.

Para preservar la semilla, salvó a quien tendía más a Su naturaleza divina. Sin embargo, como la nueva generación saliera idéntica a la sacrificada, Dios comprendió que el componente material del hombre supera al espíritu que lo insufla (Bustamante, 2005: 28).

En Azar la tensión se concentra en dos ámbitos complejos: a) el esfuerzo no sirve de nada por cuanto todo descansa en el azar, $\mathrm{y}$ b) en consecuencia, premio-castigo, elección-rechazo o bien-mal no derivan de reglas causales sino de circunstancias casuales. Un cuestionamiento que pareciera-desde la sospecha de Bustamante Zamudio-sustentar el mito cristiano y por ende el devenir de la humanidad. Una carencia absoluta de proyecto parece ser el signo transversal que se mueve por todo el abismo minificcional de Oficios de Noé, y deja al descubierto algunas preocupaciones recurrentes como la incredulidad, injusticia, temor, desobediencia y dualidad. Finalmente, en Ser o Noé ser a partir del juego de lenguaje y a propósito de la parodia que se hace a la máxima filosófica, se nos plantean dos contradicciones: la salvación como castigo y el delirio de la felicidad empañado por la desesperación. Ambas inquietudes celebran el estamento de la duda como sustento no solo de todo el universo minificcional, sino incluso, de toda la herencia recogida en los ancestrales y sagrados relatos.
La noticia del diluvio se esparció velozmente. Cada animal aspiraba a ser el elegido de su especie, pues Dios mismo les había dado el instinto de supervivencia. Todos se propusieron caer en gracia a los ojos de Noé, tal como Noé había caído en gracia a los ojos de Yavé. De acuerdo con su especialidad, tañían estruendosos llamados, hacían todo tipo de cabriolas, ejecutaban vistosas danzas, inflaban hasta reventar sus carrillos, hacían retumbar el suelo, cambiaban sus colores, daban vueltas, lamían al anciano.

La naturaleza se vistió repentinamente de una triste fiesta que celebraba una partida sin retorno. Participaban a cielo abierto los animales más recónditos, a plena luz los más taciturnos. Cada uno fue el mejor, el más veloz, el más afinado, el más seductor, el más fuerte, el más hermoso.

Sin embargo, este último esfuerzo no modificó los límites de cada uno, transferidos de todas maneras por los sobrevivientes; ni impidió una elección al azar, así Noé creyera estar eligiendo a los mejores (Bustamante, 2005: 37).

La incertidumbre como angustia existencial representa un complejo temático fundamental, no solo porque sustenta el aliento estético del universo minificcional, sino porque es el signo de todo el devenir humano. En el libro Convicciones $y$ otras debilidades mentales, tenemos un ejemplo de cómo se funden ambas aspiraciones. En el texto La incertidumbre, la ironía y el humor ocultan más que una preocupación romántica (rebeldía y soledad), el desasosiego (propio de la vanguardia) por ese malestar de duda, por esas 
inquietantes preguntas sin respuestas; en fin, por el desconcierto que asedia permanentemente al hombre de hoy:

\section{Incertidumbre}

Ha vivido apaciblemente. Se ha visto impelido a preguntas trascendentales sobre la vida, aunque rodea con un aire de escepticismo la idea de Dios: no lo niega, pero le exige una manifestación sensible que le dé certeza sobre su existencia. Es un hombre moderno. Cuando mira un crepúsculo sobrecogedor, vocifera: “¿Para qué dar estos colores a la tarde? Si hay un Dios, ¡responda!”. Acosado por la soledad y el tumulto de sus pensamientos obsesivos, suele decirse: "Si hay una fuerza sobrenatural, ¿por qué me sume en esta angustia?". Al morir una persona cercana a su corazón, demanda con todas sus fuerzas la justicia que debe reinar en el mundo. Si se entera de qué ejércitos en lucha se inspiran en sus respectivos dioses, indaga -con los ojos puestos en el cielo-si un Dios toleraría eso, que parece más bien un juego. Ante sus apuros económicos, exige que se le responda por qué debe renunciar, mientras otros viven en la más ostentosa opulencia. Cuando lo abandonan y piensa melancólico que no tiene sentido vivir, interroga cómo puede sentirse ante ello una divinidad, signada supuestamente por el atributo del amor... Sus preguntas nunca tuvieron respuesta. Ya viejo y cansado, cualquier día se recuesta a leer. Se tantea, busca con detenimiento y, finalmente, se pregunta dónde habrá dejado los anteojos. Se abren las nubes, rayos celestiales se cuelan en su habitación y una voz sublime, estentórea, llena su cabeza: "Los dejaste en la chaqueta" (Bustamante, 2002: 63).

Preguntas que interpelan la existencia de Dios, derivan de profundas reflexiones en torno a aspectos trascendentales de la vida; pero, sobre todo, descansan en la ausencia de respuestas, en el sinsentido de causas perdidas. El final mordaz hace estallar la lógica y lo trivial viene a legitimar la presencia divina. Dos ideas surgen de un posible lugar de lectura: a) la duda expresada en diversas interrogantes sustenta al pequeño abismo minificcional; $\mathrm{y}, \mathrm{b}$ ) toda idea de escepticismo se desmonta pues, en el fondo, se busca desesperadamente en Dios razones, sentidos y respuestas. En ambas perspectivas priva lo contradictorio, irónico, desconcertante y paradójico.

En relación al interés de recoger la complejidad de los procesos mentales, la penetración en los estados profundos de la conciencia y la complejización de nociones como razón y pensamiento, podemos precisar algunos textos minificcionales que exhiben estas cuestiones, develando una línea temática recurrente en la obra de Bustamante Zamudio como lo es el abordaje de un conjunto de inquietudes que podrían explicarse desde sus inclinaciones psicoanalíticas, sus preocupaciones por la compleja dimensión que conforma al lenguaje o su interés de escudriñar esa dimensión desconocida en el hombre desde la cual se mueve la lógica y el ímpetu de ruptura. Veamos el siguiente texto de su libro Roles: 


\section{El narrador}

La vida moderna le alejaba a los feligreses: poco frecuentaban el servicio religioso, ya se ilusionaban con mundos virtuales y, para religarse, sólo usaban instrumentos técnicos. El párroco se tornaba apesadumbrado, a medida que el ánimo lo abandonaba.

Alertados por este cuadro, un grupo de fieles, conocedor de un pasado no menos insaboro pero que, por contraste, le lucía añorable, se propuso darle nuevo resplandor a la congregación, nuevos bríos al cura. Sin llevar una vida especialmente disipada, inventaban pecados tradicionales y los iban confesando en dosis crecientes. El padre empezó a tocar más duro las campanas, a fruncir el entrecejo, a regañar con ahínco, a denunciar la lujuria y el vicio, el desenfreno y el libertinaje.

Sus homilías recuperaron el estilo y sus frases volvieron a tener el ímpetu que otrora había transmitido. Los parroquianos regresaron poco a poco a la iglesia, temerosos, y la vida en la congregación volvió a su normalidad. Una vez más, la creatividad narrativa había superado la realidad (Bustamante, 2007:63).

No solo la ficción supera la realidad, sino que esta, la realidad, entra en tensión desde la problematización de unas conductas que resuenan en la "creatividad narrativa". Duda, temor, ego, deseo, delirio, mundo paralelo, (in) consciente, resentimiento, represión, trauma, engaño, angustia, soledad, esquizofrenia, insomnio y depresión son solo algunos de los cuadros con los que Bustamante Zamudio explora, en su obra, el terreno psicológico desde sus misterios, patologías y crisis. La ficción ilustra la posibilidad de resca$\operatorname{tar}$ (a modo de terapia), por medio del engaño y la confección de otra realidad, al párroco de un estado apesadumbrado. Como valor agregado, notamos que es el pecado lo que le devuelve (paradójicamente) a nuestro personaje el ímpetu de sus sermones.

En Oficios de Noé, varios textos ilustran estas tensiones de orden psicológico. Por ejemplo, en Palabras y cosas se analiza la relación dicotómica entre la hospitalidad y la tormenta que pueden ser desplegadas por la palabra. La relación entre signo y símbolo es sostenida sobre el temblor, la inquietud de una realidad caótica sigue manteniendo en el vilo de la arbitrariedad y la necesidad a esa existencia inmaterial del lenguaje. Semejante idea encontramos en el texto 1,2 en el cual se plantea la imposibilidad de Noé para conciliar el sueño y ahora no tendrá más que dos ovejas para contar, con esto se limita la relación del significado y el poder evocador del lenguaje. En Evacuación se alude a una necesidad fisiológica convocada por el sueño. En el mundo onírico escapa el inconsciente y así el diluvio sería la expresión de un deseo reprimido: la liberación de esa vejiga presionada. Otro dato resulta curioso, el diluvio solo fue un sueño, nunca existió. Será que sus dimensiones, significados y simbologías también descansan en ese terreno del inconsciente.

Por su parte, Mitad y mitad es el típico relato de la dualidad, no entre bien y mal, sino entre lógica y fe. Una vez más el razonamiento es explorado desde el punto de vista religioso (condenación) y lógico (conjetura y verdad). De esta forma se 
produce un núcleo problematizador en el cual la verdad es dimensionada desde dos vectores: creer y dudar, cuya dualidad siempre es resuelta por la condenación. Pensar es un acto de rebeldía $\mathrm{y}$, por ende, condenatorio dentro de un código imperante (necesario) de obediencia y fe absoluta. La fuente del mal entonces es, según este abismo minificcional, esa constitución dual del hombre que se debate entre fe y lógica. Algo similar se plantea en el texto Creencias el cual, a través de un juego permanente con la lógica, se expresa desde tres contradicciones recurrentes: el poder lo otorga el débil a partir de su obediencia y fe, todo el discurso de la realidad se sustenta solo en la creencia y la trama de los hechos se desplaza entre el cuestionamiento y la tensión que deriva del vínculo razón-fe-saber-poder. Se trata entonces de asumir que toda existencia se sustenta fundamentalmente en el poder de la creencia.

\section{Creencias}

Dios creó al hombre. Creó en él la creencia en Dios. Y Dios habitó allí, en la creencia del hombre. El hombre creó a Dios en su creencia y lo hizo crear el mundo. Y el hombre habitó allí, en el mundo creado por Dios.

Pero el comportamiento del hombre en el mundo fue malo. Entonces, allá en la creencia del hombre, Dios se enfadó, pues su todo-poder -ilimitado para obrar sobre lo material - no estaba hecho para las cosas del corazón; y no pudo prever - en su todo-saber - el alcance de su ira hasta el punto de llevarlo a desgajar el diluvio sobre la creación. Eso sí, se aseguró de dejar un puñado de sobrevivientes, pues la creencia del insignificante hombre era la única garantía de Su existencia (Bustamante, 2005: 40).

En cuanto a la preocupación por el asunto social, podemos sintetizar algunas ideas que fluyen de nuestro escritor y resuenan en su obra, configurando de manera recurrente esa perspectiva de confrontación social: a) en el texto La ley, se infiere que la fuerza de los pequeños, de los dominados, es capaz no solo de limitar el poder, sino de controlarlo; b) en Historia se hace evidente que el reflejo de los acontecimientos se sustenta en la necesidad de testimoniar (y explicar) lo desconocido, lo que implica que existe un terreno del devenir histórico que descansa en lo probable dado que todo se acomoda para que encaje más que en la veracidad de los hechos, en la ilusión de realismo con la cual se construye el discurso de la historia.

Por su parte, c) en Alianza observamos que ésta se da verdaderamente no entre el hombre y la divinidad, sino entre los hombres a partir de una convicción de lucha y militancia social, en la cual se reivindica su importancia en la legitimación del poder, a fin de cuentas, la pugna social puede cambiar el curso de la historia; d) finalmente, en Animal de costumbres el concepto de individuo es desplazado por una masa colectiva de obediencia ciega. Así, la idea de rebaño otorga esa conforme alegría sustentada en la inacción e ignorancia.

\section{Alianza}

- Voy a dejar caer sobre el mundo toda el agua que es posible inventar, pues el hombre no es digno de la creación —dijo Dios a Noé. 
- ¿Y por qué te ocupas de criaturas tan insignificantes como nosotros? ¿No está el universo mundo poblado de manera variada e innumerable?

-Sois soberbios - explicó el Señor.

- ¿Y qué alcance puede tener la soberbia de una criatura entre tantas? ¿Qué puede destruir si el universo es infinito? ¿A quién puede ofender que no sea a sí mismo?

-No honráis a vuestro Dios.

-Tú necesitas al hombre, por eso buscas salvarme. Si no te importa, quiero morir con los míos.

-Está bien, no lleguemos a extremos. No habrá exterminio de la carne por el agua del diluvio. No habrá diluvio que asole la tierra. -Te entendemos - dijo Noé-. Hagamos una Alianza: cada vez que el arco iris aparezca entre las nubes, nos acordaremos de ti (Bustamante, 2005: 48).

De estas relaciones podemos advertir que el discurso mítico surge como un mecanismo de dominación, aunque se ampara en la necesidad de encontrar una posible explicación a lo desconocido, su verdadero propósito es promover la obediencia como forma de control. Sin embargo, Bustamante Zamudio es recurrente al asumir en su creación que solo la acción y voluntad de los hombres legitima o transforma radicalmente esas relaciones de poder. En el texto Precaución de su libro Disposiciones y virtudes, podemos advertir, por un lado, una síntesis de este último planteamiento, del cual se infiere la idea de azar que subsume el poder de la voluntad y acción de los hombres; y por el otro, la complejidad del temor visto desde la paradoja de un ser temido que ahora es temeroso, por ello intenta tomar precauciones y guardar distancias:

\section{Precaución}

Un Dios se ocupa de casi todo: el ascenso de líquidos por la raíz, el minucioso aleteo del mosquito, los dilatados ciclos de los astros, la acumulación organizada de materia que será un cristal, las conjunciones siderales, la respiración de una hoja, la duplicación del espejo... Pequeño, inmenso, infinito, unánime, simple, complejo... no constituye un reto para él. Pero, frente a los hombres, si toma precauciones: no interviene en su devenir, parece temerles, los deja a un azar que ellos llaman libertad (Bustamante, 2016: 51).

\section{(In)conclusión: parte resolutiva}

Una vez presentados el conjunto de argumentos teóricos, metodológicos y literarios que sustentan las pretensiones de este artículo, se concluye:

a. La lectura del texto minificcional va de la indagación o recopilación de pistas hacia el ejercicio propiamente comprensivo e interpretativo que permite advertir los múltiples sentidos y significados que el texto despliega. b. Los juicios que devienen del proceso hermenéutico son siempre inacabados, abiertos, flexibles y múltiples. De esta forma culpable o absuelto, el lector como co-productor de sentidos se mueve por un abismo lleno de incertidumbres, juegos y rupturas. 
c. La desacralización no se presenta solo en el terreno reescritural como una forma de diluir los grandes relatos, también son puestos en tensión los cánones literarios y los propios desafíos implicados en el proceso lector.

d. Con cada nueva producción minificcional se apuesta a la desacralización, con cada lectura se apuesta a un juicio siempre relativo y opcional.

e. El minúsculo fragmento minificcional, siempre subversivo, es al mismo tiempo un amplio océano de interpretaciones, un laberinto insondable de lecturas posibles; en fin, un universo repleto de juegos, sospechas y trasgresiones.

\section{Referencias citadas}

Bustamante, G. (2002): Convicciones y otras debilidades mentales, lera. Edición, Cali, Deriva ediciones.

Bustamante, G. (2005): Oficios de Noé, 1era. Edición, Bogotá, Común presencia editores.

Bustamante, G. (2007): Roles, lera. Edición, Bucaramanga, Fondo editorial Universidad Industrial de Santander.

Bustamante, G. (2016): Disposiciones y virtudes, lera. Edición, Cali, Deriva ediciones.

Guillén, C. (1985): Entre lo uno y lo diverso. Introducción a la literatura comparada, Barcelona, Editorial Crítica.

Piglia, R. (1986). Crítica y ficción, Barcelona, Editorial Anagrama. 